\title{
Three New -CF3, -CN Containing $\pi$-Conjugated Heteroaromatic Compounds: Synthesis, Crystal Structure and Photoelectronic Properties
}

\author{
Tetsuji Moriguchi1* ${ }^{*}$ Daisuke Yakeya1, Venkataprasad Jalli2 \\ ${ }^{1}$ Department of Applied Chemistry, Faculty of Engineering, Kyushu Institute of Technology, Kitakyushu, Japan \\ ${ }^{2}$ Research and Development Division, Sankar Foundation, Visakhapatnam, India \\ Email: *moriguch@che.kyutech.ac.jp
}

How to cite this paper: Moriguchi, T., Yakeya, D. and Jalli, V. (2018) Three New -CF3, -CN Containing $\pi$-Conjugated Heteroaromatic Compounds: Synthesis, Crystal structure and Photoelectronic Properties. Crystal Structure Theory and Applications, 7, 33-45.

https://doi.org/10.4236/csta.2018.73003

Received: July 26, 2018

Accepted: August 28, 2018

Published: August 31, 2018

Copyright $\odot 2018$ by authors and Scientific Research Publishing Inc. This work is licensed under the Creative Commons Attribution International License (CC BY 4.0).

http://creativecommons.org/licenses/by/4.0/

(c) (i) Open Access

\begin{abstract}
Three new $\pi$-conjugated hetero aromatic materials consisting of pyridine $3 a$, furan $3 \mathbf{b}$, and thiophene $3 c$ have been synthesized by Knoevenagel condensation reaction. These molecules have been characterized by ${ }^{1} \mathrm{H}$ NMR, EI-MS and single crystal X-ray diffraction analysis. Molecule 3a crystallized under monoclinic system with space group $C 2 / \mathcal{c}$, molecule $3 \mathbf{b}$ crystallized under triclinic system with space group $P-1$ and the molecule $3 c$ crystalized under triclinic system with space group $P$-1. The optoelectronic properties of these compounds have been studied. Molecules $3 a, 3 b$ and $3 c$ showed strong absorption maxima wavelengths at 300,419 and $418 \mathrm{~nm}$, respectively. The molar extinction coefficients $(\varepsilon)$ of the compounds $3 \mathrm{a}, 3 \mathrm{~b}$ and $3 \mathrm{c}$ suggested that molecule $3 \mathbf{b}$ has better ability to absorb UV light; molecule $3 a$ has better fluorescence intensity than molecule $\mathbf{3 b}$ and $\mathbf{3 c}$. Low energy gaps of HOMO and LUMO energy levels of these compounds suggests that these compounds may be a promising new class of lead compounds for developing high performance semiconductor materials. Compounds $3 \mathrm{a}, 3 \mathrm{~b}$ and $3 c$ has emissions near to blue light, a slight modification of the structures by extending conjugation may find important applications in optoelectronic devices as blue light emitters in organic light-emitting devices for the development of new generation organic semiconducting materials.
\end{abstract}

\section{Keywords}

Organic Semiconducting Material, Knoevenagel Condensation, X-Ray Analysis, $\pi$-Conjugated Materials 


\section{Introduction}

$\pi$-Conjugated systems are building blocks of organic semiconductors and have been of great interest due to their important applications in organic electronic circuits as semiconducting materials [1]-[7]. They have been used as semiconducting materials in organic photovoltaic cells, sensors, organic light-emitting diodes and organic field-effect transistors (OFETs) due to the offering of low-cost, large-area, and flexible electronic devices [8] [9] [10] [11]. N-type semiconductor materials are precise components in ambipolar transistors and complementary circuits [12] [13]. However, due to their limitations such as low air stability and difficult in design, synthesis these materials are being less explored. It has been documented that air stability and performance of n-type semiconducting material can be improved by substituting electron withdrawing groups such as fluorine, cyano, carbonyl etc. into the n-type semiconducting material [14]. It was reported that incorporation of electron withdrawing groups increases the air stability of their anions due to increase in electron affinity of materials, LUMO energy gap will be reduced [15] [16] [17]. Jones and co-workers have explored the n-type air stable perylenediimide derivatives by incorporating cyano $(\mathrm{CN})$ and fluorine (F) substituent [18] [19]. Recently, we reported n-type transport characteristics of $p$-phenylenevinylene derivative of $3^{\prime}, 3^{\prime}-\left(1,4\right.$-phenylene)bis $\left\{2^{\prime}\right.$ (4"'-trifluoromethyl)phenyl acrylonitorile having two cyano $(\mathrm{CN})$ and two trifluoromethyl $\left(\mathrm{CF}_{3}\right)$ substituents [20]. We also reported the synthesis of 2,5Difluoro-1,4-phenylene-bis\{2-[4-(trifluoromethyl)phenyl]acrylonitrile $\}$ and fabricated OFET using this compound exhibited good n-channel OTFT properties with high electron mobility [21]. Herein, we report the synthesis, crystal structure and photoelectronic properties of three $\pi$-conjugated heteroaromatic materials having pyridine, furan, and thiophene and cyano, fluorine as electron withdrawing substituents. We hope this structural-property study will provide better insight for material chemists in designing more efficient and air resistant organic semiconducting materials, which are strongly desired for next generation optoelectronic application.

\section{Experimental}

\subsection{Materials and Methods}

All reagents were purchased from TCI and Sigma Aldrich and used without further purification. All the products were characterized by ${ }^{1} \mathrm{H}$ NMR, EI-MS and X-ray diffraction analysis. The NMR spectrum was recorded on a Bruker AMX-500 MHz instrument (Bruker, Yokohama, Japan) at room temperature. Absorption spectrum was measured by using JASCO V-550 UV/VIS Spectrophotometer (JASCO Corporation, Tokyo, Japan) and Fluorescence spectrum was measured by using Hitachi F-2500 Fluorescence Spectrophotometer (Hitachi High-Technologies Corporation, Tokyo, Japan). X-ray data for the compound were collected at room temperature using a Bruker Apex II KY CCD diffractometer with graphite 
monochromated MoKa radiation $(\lambda=0.71073 \AA)$ with $\omega$-scan method.

\subsection{Synthesis of Compounds $3 a, 3 b$ and $3 c$}

In a first Schlenk vessel 2,6-pyridine dicorboxaldehyde (1a) or 2,5-furan dicorboxaldehyde (1b) or 2,5-thiophene dicorboxaldehyde (1c) $(680 \mathrm{mg}, 0.40 \mathrm{mmol})$ and (4-trifluoromethyl)phenylacetonitrile $2(740 \mathrm{mg}, 0.40 \mathrm{mmol}$ ) were taken in absolute ethanol $(50 \mathrm{~mL})$. In a second Schlenk vessel, sodiumethoxide $(0.400 \mathrm{~g}$, $5.76 \mathrm{mmol})$ and freshly distilled dry pyridine $(4.96 \mathrm{mmol}, 0.40 \mathrm{~mL})$ were taken in absolute ethanol $(50 \mathrm{~mL})$. The mixture was mixed and heated to reflux for 3 hours. Then, pyridine and volatiles were removed under reduced pressure. The residue was repeatedly extracted with small portions $(15 \mathrm{~mL})$ of dichloromethane. The organic layer was washed with water, dried over anhydrous $\mathrm{MgSO}_{4}$, and then, filtered through a syringe filter. The extract was evaporated under reduced pressure to leave the residue affording the compounds $\mathbf{3 a}, \mathbf{3 b}$ and $\mathbf{3 c}$ in quantitative yield.

3a ${ }^{1} \mathrm{H}$ NMR $\left(\mathrm{CDCl}_{3}, 400 \mathrm{MHz}\right) \delta=7.75(4 \mathrm{H}, \mathrm{d}, \mathrm{Ar}-\mathrm{H}), 7.78(2 \mathrm{H}, \mathrm{s}, \mathrm{CH}=\mathrm{CN})$, 7.89 (4H, d, Ar-H), 7.98 1H, q, Ar-H), 8.04 (2H, s, Ar-H), 8.05 (2H, s-m, Ar-H); EI-MS: $\mathrm{M}^{+}, 468$.

3b ${ }^{1} \mathrm{H}$ NMR $\left(\mathrm{CDCl}_{3}, 400 \mathrm{MHz}\right) \delta=7.40(2 \mathrm{H}, \mathrm{s}, \mathrm{Ar}-\mathrm{H}), 7.52(2 \mathrm{H}, \mathrm{s}, \mathrm{CH}=\mathrm{CN})$, $7.72(2 \mathrm{H}, \mathrm{d}, \mathrm{Ar}-\mathrm{H}), 7.80$ (2H, d, Ar-H); EI-MS: $\mathrm{M}^{+}, 457$.

$3 \mathrm{c}{ }^{1} \mathrm{H}$ NMR $\left(\mathrm{CDCl}_{3}, 400 \mathrm{MHz}\right) \delta=7.72(6 \mathrm{H}, \mathrm{m}, \mathrm{Ar}-\mathrm{H}), 7.79(4 \mathrm{H}, \mathrm{d}, \mathrm{Ar}-\mathrm{H})$, $7.88(2 \mathrm{H}, \mathrm{s}, \mathrm{CH}=\mathrm{CN})$; EI-MS: $\mathrm{M}^{+}, 473$.

\subsection{Single-Crystal X-Ray Analysis and Structure Determination}

Crystallographic and structural refinement data for $3 a, 3 b$ and $3 c$ summarized in Table 1 . Single crystals of $\mathbf{3 a}, \mathbf{3 b}$ and $\mathbf{3 c}$ were easily obtained at room temperature from a solution of dichloromethane using slow diffusion technique. Crystals of $\mathbf{3 a}, \mathbf{3 b}$ and $\mathbf{3 c}$ measuring good dimensions were mounted on a glass fiber. The data were collected on a Bruker APEX II KY CCD diffractometer by using a graphite-monochromatized $\mathrm{Mo} / \mathrm{Ka}$ radiation $(\lambda=0.71073 \AA)$ and a nominal crystal-to-area detector distance of ca. $83 \mathrm{~mm}$.

APEX2 software was used for preliminary determination of the unit cell. Determination of integral intensities [22] and unit cell refinement were performed using SAINT program [23]. And, data were corrected for absorption effects with SADABS using the empirical technique [24]. The structures were solved by the SHELXS-2014/7 direct method, and subsequent structure refinements were performed using SHELXL-2014/7.

\section{Results and Discussion}

The three $n$-type semiconducting materials $\mathbf{3 a}, \mathbf{3 b}$ and $\mathbf{3} \mathbf{c}$ have been synthesized by Knoevenagel condensation of pyridine dicorboxaldehyde 1a, furan dicorboxaldehyde $1 \mathrm{~b}$, thiophene dicorboxaldehyde $1 \mathrm{c}$ with 4 -(trifluoromethyl) phenyl acrylonitrile 2 in the presence of sodium ethoxide (Scheme 1, Scheme 2). Compounds $\mathbf{3 a}, \mathbf{3 b}$ and $\mathbf{3} \mathbf{c}$ have been characterized with ${ }^{1} \mathrm{H}$ NMR and EI-MS. 
Table 1. Crystal data and structure refinements for $3 a, 3 b$ and $3 \mathbf{c}$.

\begin{tabular}{|c|c|c|c|}
\hline parameters measured & $3 a$ & $3 b$ & $3 c$ \\
\hline Empirical Formula & $\mathrm{C}_{25} \mathrm{H}_{13} \mathrm{~F}_{6} \mathrm{~N}_{3}$ & $\mathrm{C}_{24} \mathrm{H}_{12} \mathrm{~F}_{6} \mathrm{~N}_{2} \mathrm{O}$ & $2\left(\mathrm{C}_{24} \mathrm{H}_{12} \mathrm{~F}_{6} \mathrm{~N}_{2} \mathrm{~S}\right) \cdot \mathrm{C} \mathrm{H}_{6}$ \\
\hline Formula Weight $\left(\mathrm{g} \cdot \mathrm{mol}^{-1}\right)$ & 469.38 & 458.38 & 1026.94 \\
\hline Crystal shape, color & Prism, yellow & Needle, colorless & Prism, colorless \\
\hline Temperature & $120 \mathrm{~K}$ & $90 \mathrm{~K}$ & $120 \mathrm{~K}$ \\
\hline Radiation type & Mo Ka & Mo Ka & Mo Ka \\
\hline Wavelength $(\AA)$ & 0.7107 & 0.7107 & 0.7107 \\
\hline Crystal system & Monoclinic & Triclinic & Triclinic \\
\hline Space group & $C 2 / c$ & $P-1$ & $P-1$ \\
\hline Unit cell dimensions & $\begin{array}{c}\mathrm{a}=11.2641(15) \AA \\
\mathrm{b}=18.568(2) \AA \\
\mathrm{c}=10.0628(15) \AA \\
\alpha=90^{\circ} \\
\beta=103.960(1)^{\circ} \\
\gamma=90^{\circ}\end{array}$ & $\begin{array}{c}\mathrm{a}=4.470(5) \AA \\
\mathrm{b}=13.016(15) \AA \\
\mathrm{c}=16.904(19) \AA \\
\alpha=79.018(11)^{\circ} \\
\beta=88.236(12)^{\circ} \\
\gamma=83.602(11)^{\circ}\end{array}$ & $\begin{array}{l}\mathrm{a}=7.5572(14) \AA \\
\mathrm{b}=15.746(3) \AA \\
\mathrm{c}=19.641(4) \AA \\
\alpha=84.754(2)^{\circ} \\
\beta=80.546(2)^{\circ} \\
\gamma=80.620(2)^{\circ}\end{array}$ \\
\hline Volume & $2042.5(5) \AA^{3}$ & $959.4(19) \AA^{3}$ & $2269.6(7) \AA^{3}$ \\
\hline $\mathrm{Z}$ & 4 & 2 & 2 \\
\hline Calculated density $\left(\mathrm{Mg} \cdot \mathrm{m}^{-3}\right)$ & 1.526 & 1.587 & 1.503 \\
\hline Absorption coefficient $\mathrm{mm}^{-1}$ & 0.130 & 0.138 & 0.212 \\
\hline$F(000)$ & 952 & 464 & 1044 \\
\hline Crystal Size (mm) & $0.30 \times 0.20 \times 0.20$ & $0.20 \times 0.15 \times 0.10$ & $0.40 \times 0.20 \times 0.20$ \\
\hline Theta range for data collection & $2.2^{\circ}$ to $25^{\circ}$ & $1.23^{\circ}$ to $23.91^{\circ}$ & $1.1^{\circ}$ to $25.0^{\circ}$ \\
\hline Limiting indices & $\begin{array}{c}-13<h<13 \\
-22<k<22 \\
-11<l<11\end{array}$ & $\begin{array}{c}-5<h<5 \\
-14<k<14 \\
-19<1<19\end{array}$ & $\begin{array}{c}-8<h<8 \\
-18<k<18 \\
-23<1<23\end{array}$ \\
\hline $\begin{array}{c}\text { Reflections } \\
\text { collected/unique }\end{array}$ & $\begin{array}{c}9738 / 1807 \\
{[R \text { int }=0.023]}\end{array}$ & $\begin{array}{c}7410 / 2919 \\
{[\text { Rint }=0.046]}\end{array}$ & $\begin{array}{c}21937 / 7990 \\
{[\text { Rint }=0.033]}\end{array}$ \\
\hline Completeness to theta (\%) & 99.9 & 99.7 & 99.2 \\
\hline
\end{tabular}<smiles>CCON(CC)CCOCCN(CC)c1ccc(C(F)(F)F)cc1</smiles>

Scheme 1. Schematic representation of synthesis of compound 3a.

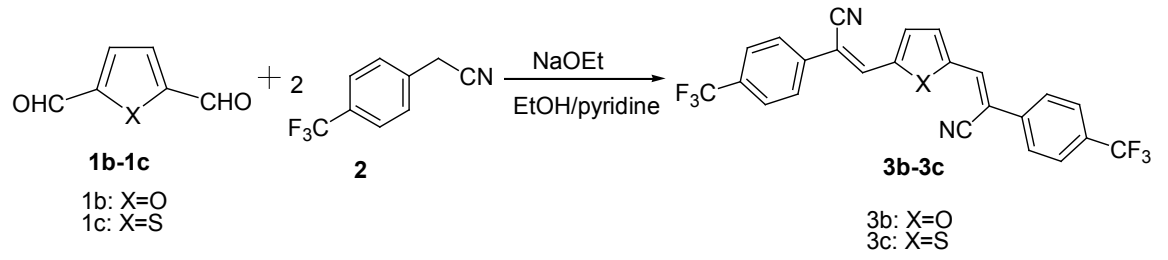

Scheme 2. Schematic representation of synthesis of compound $\mathbf{3 b}$ and $\mathbf{3 c}$. 
Further to confirm the molecular structures of molecules $3 a, 3 b$ and $3 c$, suitable crystals for X-ray diffraction analysis were obtained by the slow evaporation of dichloromethane solution using slow diffusion method. The crystallographic details are summarized in Table 1 . The compound 3 a crystallizes with monoclinic crystal system, space group $C 2 / c$. The molecular structure of $3 \mathrm{a}$ was depicted in Figure 1.

The asymmetric unit of the title compound $\mathrm{C}_{25} \mathrm{H}_{13} \mathrm{~F}_{6} \mathrm{~N}_{3}$, contains one-half of the formula unit. The molecular structure appears to be planar from the top view. But, from the side view we can clearly see that three aromatic rings are slightly distorted from the planar geometry. Two aromatic ring planes, A (defined by C7, C8, C9, C10, C11, C12) and B (defined by N1, C1, C2, C3, C2, C1) were slightly leaned and the plane angles between two aromatic rings is $2.58^{\circ}$ as shown in Figure 1. The two cyano groups, which are located in the same direction causes a deviation from planarity of the molecule 3a. Triple bond lengths of the cyano group was 1.145 (2) A for C6N2. On the other hand, the bond angle consisting cyanoethenyl C-CN triple bond was slightly twisted, the angles is $173.95(2)^{\circ}$ for C5-C6-N2.

Crystal packing of the molecule $3 \mathrm{a}$ was also illustrated in Figure 2. Intermolecular short contacts of the molecule 3 a were listed in Table 2. The molecular packing of the molecule $3 a$ has layer like geometry. In the crystal packing diagram, $\mathrm{C}-\mathrm{H} \cdots \mathrm{N}$ and $\mathrm{C} \cdot . \mathrm{C}$ short contacts between the molecules generated three dimensional molecular networks.

The compound $3 \mathrm{~b}$ crystallizes with triclinic crystal system, space group $P-1$. The molecular structure and packing diagram of $3 \mathbf{b}$ was depicted in Figure 3.

The molecule $3 \mathrm{~b}$ appears to be planar from the top. But, from the side view clearly appears that molecule $\mathbf{3 b}$ is a strained one. Three aromatic ring planes, $\mathrm{A}$ (defined by C18, C19, C20, C21, C22, C23), B (defined by C1, C2, C3, C4, O1) and $\mathrm{C}$ (defined by C8, C9, C10, C11, C12, C13) were slightly leaned and the plane angles between three aromatic ring moieties are $5.67^{\circ}$ for $\mathrm{A}-\mathrm{B}, 25.27^{\circ}$ for

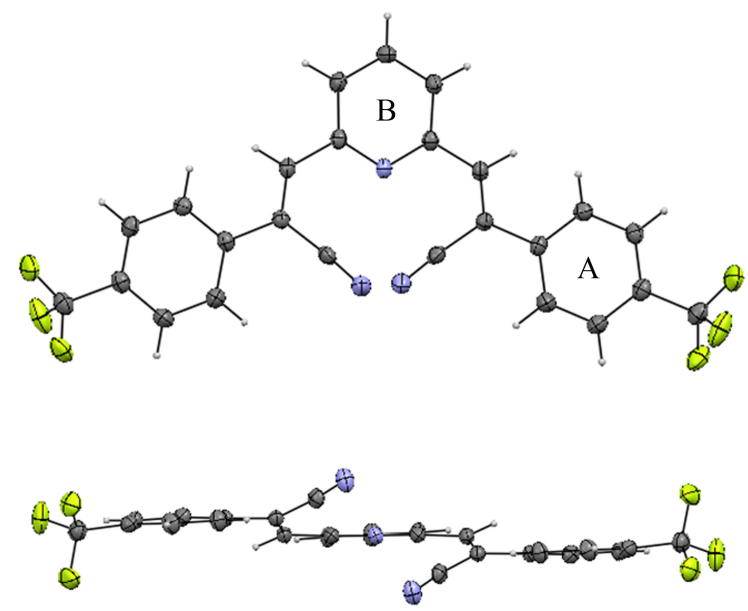

Figure 1. Top (above) and side (below) views of the molecule $3 \mathrm{a}$ and thermal ellipsoids are drawn on $50 \%$ probability level. A and B represents phenyl and pyridine rings. 


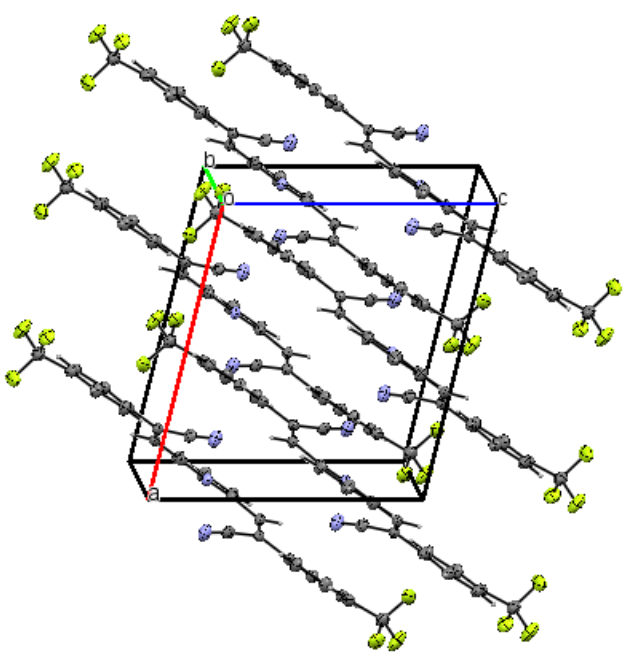

Figure 2. Molecular packing of the compound 3a and thermal ellipsoids are drawn on $50 \%$ probability level. Blue and pale green ellipsoids represents $\mathrm{N}$ and $\mathrm{F}$ atoms, respectively.

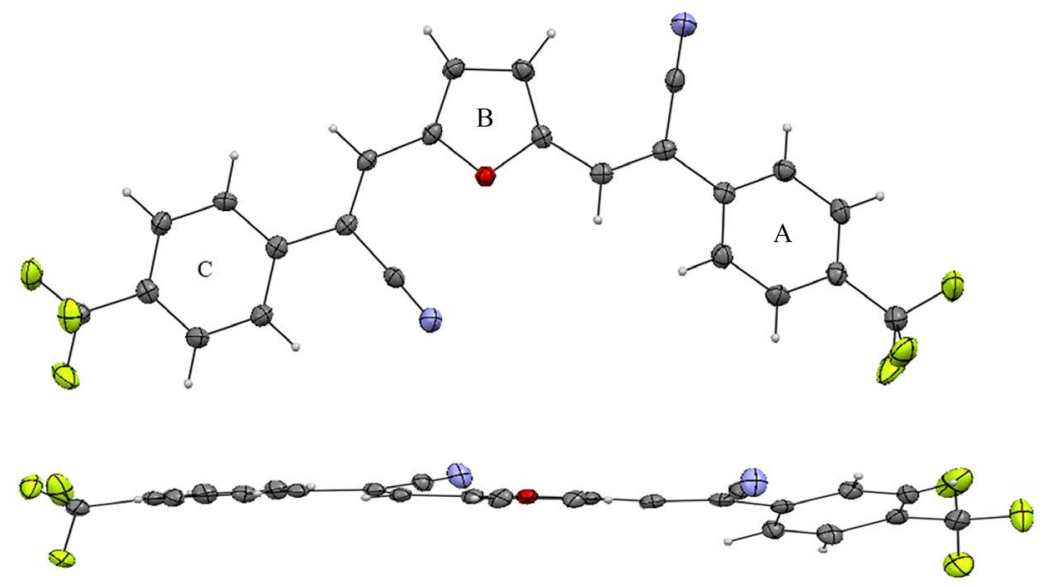

Figure 3. Top (above) and side (below) views of the molecule $\mathbf{3 b}$ and thermal ellipsoids are drawn on $50 \%$ probability level. A, B and C represents phenyl and furan rings.

Table 2. Selected intermolecular short contacts $(\AA)$ of the molecule $3 \mathbf{a}$.

\begin{tabular}{cccc}
\hline \multicolumn{2}{c}{ Short contacts (between the sidecolumns) } & \multicolumn{2}{c}{ Short contacts (between molecules in the column) } \\
\hline N2-H4 & 2.695 & C4-C4 & 3.341 \\
N2-H9 & 2.596 & C4-C1 & 3.372 \\
\hline
\end{tabular}

$\mathrm{A}-\mathrm{C}$ and $5.67^{\circ}$ for $\mathrm{B}-\mathrm{C}$ respectively as shown in Figure 1 . The plane angel between the end phenyl rings is $25.27^{\circ}$, this suggests that molecule $3 \mathrm{~b}$ is a strained one. Triple bond lengths of the cyano groups were 1.137 (4) $\AA$ for C7N1 and 1.139 (4) $\AA$ for $\mathrm{C} 17 \mathrm{~N} 2$, respectively. The bond angle consisting cyanoethenyl $\mathrm{C}-\mathrm{CN}$ triple bonds are slightly twisted, the angles are $177.78(4)^{\circ}$ for C6-C7-N1 and $179.2(4)^{\circ}$ for C16-C17-N2, respectively.

Crystal packing of the molecule $3 \mathrm{~b}$ was also illustrated in Figure 4. Intermolecular short contacts of the molecule $\mathbf{3 b}$ were listed in Table 3 . The molecular 
Table 3. Selected intermolecular short contacts $(\AA)$ of the molecule $3 \mathbf{b}$.

\begin{tabular}{cccc}
\hline Short contacts (between the sidecolumns) & Short contacts (between molecules in the column) \\
\hline F6-H3 & 2.510 & & \\
H12-N1 & 2.702 & C4-C5 & 3.367 \\
F2-H11 & 2.491 & C5-C13 & 3.370 \\
F2-H6 & 2.595 & C12-F3 & 3.145 \\
F3-F3 & 2.754 & & \\
\hline
\end{tabular}

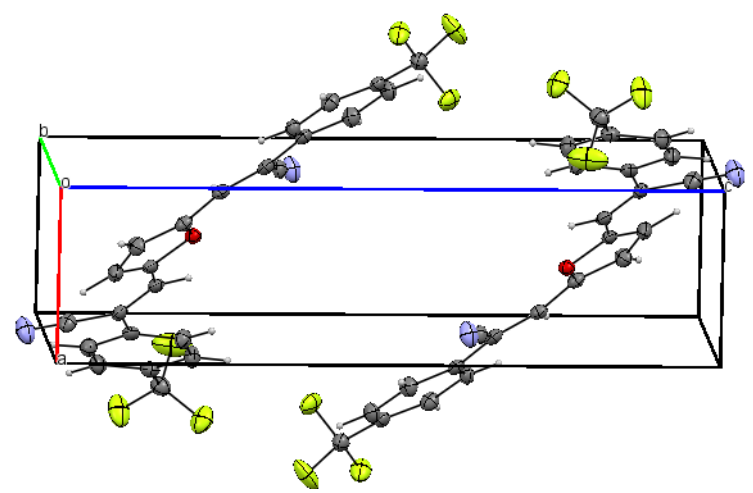

Figure 4. Molecular packing of the compound $\mathbf{3 b}$ and thermal ellipsoids are drawn on $50 \%$ probability level. Blue, red and pale green ellipsoids represents N, O and F atoms, respectively.

packing of the molecule $3 \mathrm{~b}$ has layer like geometry. In the crystal packing diagram $\mathrm{C}-\mathrm{H} \cdots \mathrm{N}, \mathrm{C}-\mathrm{H} \cdots \mathrm{F}$ and $\mathrm{C} \cdots \mathrm{C}$ short contacts between the molecules generated three dimensional molecular networks.

The compound $3 c$ crystallizes with triclinic crystal system, space group $P-1$ with two moleucles and one benzene solvent molecule in the unit cell. The molecular structure and packing diagram of $3 \mathrm{c}$ was depicted in Figure 5.

The molecule $3 \mathrm{c}$ appears to be perfect planar from the top and side views. Three aromatic ring planes, A (defined by C8, C9, C10, C11, C12, C13), B (defined by C1, C2, C3, C4, S1) and C (defined by C18, C19, C20, C21, C22, C23) were slightly leaned (Figure 1 ) and the planeangles between three phenyl moieties are $2.11^{\circ}$ for $\mathrm{A}-\mathrm{B}, 6.42^{\circ}$ for $\mathrm{A}-\mathrm{C}$ and $7.92^{\circ}$ for $\mathrm{B}-\mathrm{C}$ respectively. The plane angel between the end phenyl rings is $7.92^{\circ}$, this suggests that molecule $3 \mathrm{~b}$ is less strained one than molecules $3 a$ and $3 b$. Due to this reason electron carrier mobility of molecule $3 c$ seems to be relatively good compared with the compounds $3 \mathrm{a}$ and $3 \mathrm{~b}$. Triple bond lengths of the cyano groups were 1.145 (3) $\AA$ for $\mathrm{C} 17 \mathrm{~N} 1$ and 1.147 (4) $\AA$ for C7N2, respectively. The bond angle consisting cyanoethenyl $\mathrm{C}-\mathrm{CN}$ triple bonds are slightly twisted, the angles are 178.88 (2) ${ }^{\circ}$ for $\mathrm{C} 16-\mathrm{C} 17-$ $\mathrm{N} 1$ and 177.98 (2) ${ }^{\circ}$ for C6-C7-N2, respectively.

Crystal packing of the molecule $3 \mathrm{c}$ was also illustrated in Figure 6. Intermolecular short contacts of the molecule $3 \mathrm{c}$ were listed in Table 4 . In the crystal packing diagram $\mathrm{C}-\mathrm{H} \cdots \mathrm{N}, \mathrm{C}-\mathrm{H} \cdots \mathrm{F}$ and $\mathrm{C} \cdots \mathrm{C}$ short contacts between the molecules generated three dimensional molecular networks.

Further, the photophysical properties of molecules $\mathbf{3 a}, \mathbf{3 b}$ and $\mathbf{3 c}$, the UV-Vis 

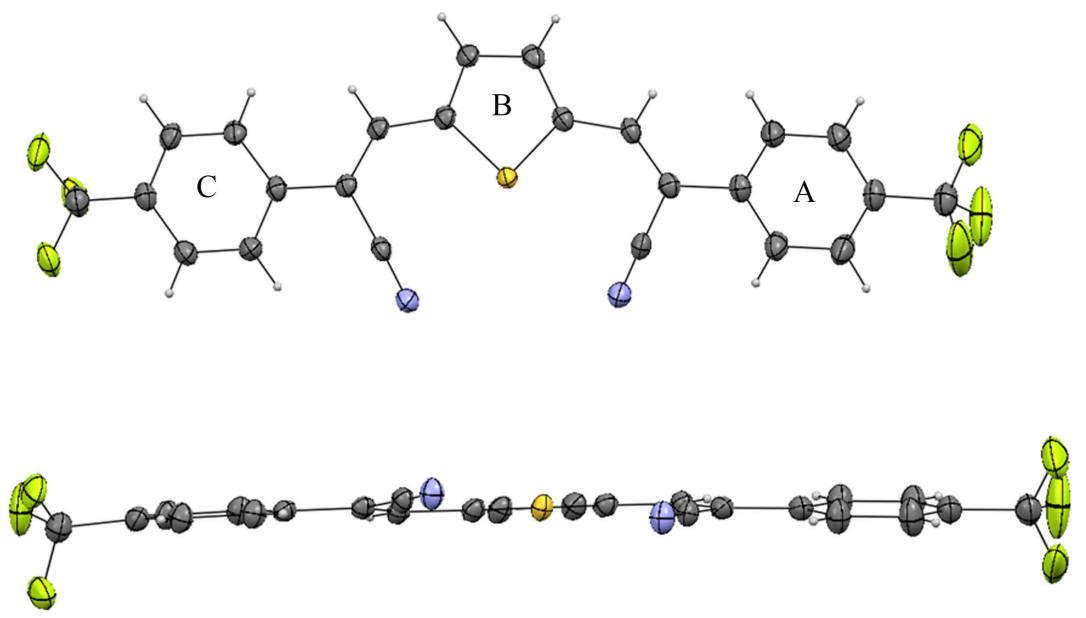

Figure 5. Top (above) and side (below) views of the molecule $3 \mathrm{c}$ and thermal ellipsoids are drawn on $50 \%$ probability level. A, B and C represents phenyl and thiophene rings.

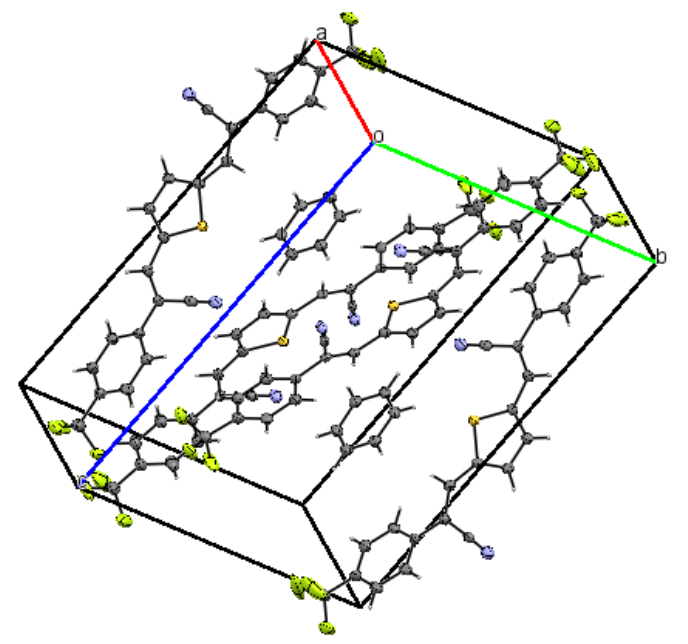

Figure 6. Molecular packing of the compound 3c and thermal ellipsoids are drawn on $50 \%$ probability level. Blue, yellow and pale green ellipsoids represents $\mathrm{N}, \mathrm{S}$ and $\mathrm{F}$ atoms, respectively.

Table 4. Selected intermolecular short contacts $(\AA)$ of the molecule 3c.

\begin{tabular}{cccc}
\hline Short contacts (between the sidecolumns) & Short contacts (between molecules in the column) \\
\hline H2-N3 & 2.621 & & \\
N2-H27 & 2.433 & & 3.157 \\
H3-N4 & 2.720 & F3-C19 & 3.157 \\
N1-H36 & 2.626 & C20-F8 & 3.145 \\
H23-F7 & 2.597 & C12-F3 & 3.109 \\
N2-H53 & 2.705 & F12-C33 & 3.383 \\
H9-C51 & 2.878 & C29-C43 & 3.021 \\
F11-H34 & 2.508 & F11-C34 & \\
H43-C53 & 2.792 & & \\
H37-C50 & 2.855 & & \\
\hline
\end{tabular}

absorption and Fluorescence emission of the molecules $\mathbf{3 a}, \mathbf{3 b}$ and $\mathbf{3 c}$ were measured in dichloromethane solution $\left(1 \times 10^{-5} \mathrm{~mol} / \mathrm{L}\right)$, and their correspond- 
ing spectra were shown in Figure 7 and Figure 8, respectively. The molecules $3 \mathrm{a}, 3 \mathrm{~b}$ and $3 \mathrm{c}$ displayed absorption maxima wavelength at 300,419 and $418 \mathrm{~nm}$, respectively.

The molar extinctinction coefficients $(\varepsilon)$ of the compounds $3 \mathrm{a}, 3 \mathrm{~b}$ and $3 \mathrm{c}$ were calculated as $2.4 \times 10^{4}(300 \mathrm{~nm}), 4.9 \times 10^{4}(419 \mathrm{~nm})$ and $4.1 \times 10^{4}(418 \mathrm{~nm})$, $\mathrm{L} \cdot \mathrm{mol}^{-1} \cdot \mathrm{cm}^{-1}$, respectively. As a basic rule, the molecule, which has higher extended $\pi$-conjugation shows better UV light absorbance. Conversely, molecule $3 \mathrm{a}$, which has higher conjugated $\pi$-system has less absorbance than molecules $\mathbf{3 b}$ and $3 \mathrm{c}$. This may be due to the relatively highly strained geometry of molecule $3 \mathrm{a}$ resulted in less $\pi$-orbital overlap. Among three molecules, $3 \mathrm{~b}$ has better

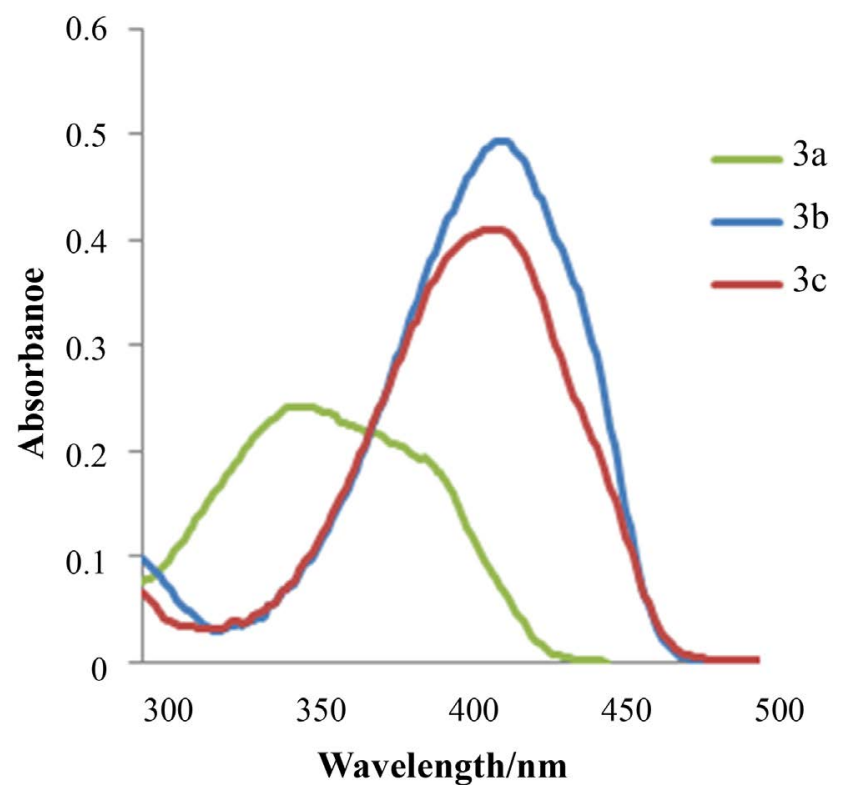

Figure 7. UV-Visible absorption spectra of molecules $\mathbf{3 a}, \mathbf{3 b}$ and $\mathbf{3 c}$.

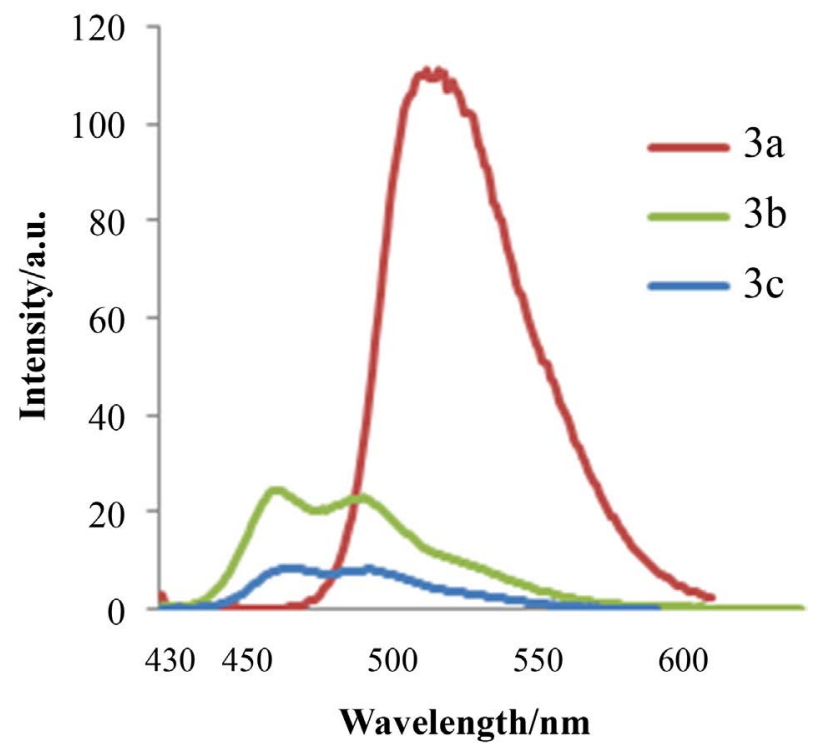

Figure 8. Emission spectra of molecules $3 a, 3 b$ and $3 c$. 
ability to absorb UV light because two cyano groups in molecule $3 \mathbf{b}$ are far away to each other may be facilitated the effective $\pi$-orbital overlap.

The emission spectra of the molecules $3 \mathrm{a}, 3 \mathrm{~b}$ and $3 \mathrm{c}$ were recorded in dichloromethane solution $\left(1 \times 10^{-5} \mathrm{~mol} / \mathrm{L}\right)$, and their emission spectra is shown in Figure 8. Emission spectra of the complexes were measured by exciting the complexes at their absorption maxima wavelengths 300,419 and $418 \mathrm{~nm}$, respectively. Among three molecules, $3 \mathrm{a}$ has better fluorescence ability than molecule $\mathbf{3 b}$ and $\mathbf{3 c}$. This may be due to the extended conjugation of molecule $\mathbf{3 a}$ due to pyridine moity than molecule $3 b$ and $3 c$, which has furan and thiophene moity in their structures. Noteworthy points from the structural and photophysical properties are these compounds have emissions near to blue light. Further with slight modification of these structures by extending conjugation may find important applications in optoelectronic devices, such as blue emitters in organic light-emitting devices (OLEDs) for the development of new generation organic semiconducting materials.

Further, HOMO and LUMO energy level calculations of the $\pi$-systems of the compounds were carried out using density functional theory (DFT) B3LYP 6 $31 \mathrm{G}(\mathrm{d})$ level on SPARTAN16 Suite program [25]. Atomic coordinate data ( $x, y$, $z$ ) of the X-ray analysis were used in calculations. The calculation results were HOMO $-6.52 \mathrm{eV}$, LUMO $-2.52 \mathrm{eV}$ for 3a, HOMO $-6.05 \mathrm{eV}$, LUMO $-3.07 \mathrm{eV}$ for $3 \mathrm{~b}$ and HOMO $-5.93 \mathrm{eV}$, LUMO $-3.93 \mathrm{eV}$ for $3 \mathrm{c}$ (Figure 9). The energy gaps were $3.79 \mathrm{eV}$ for $3 \mathrm{a}, 3.88 \mathrm{eV}$ for $3 \mathrm{~b}$ and $3.73 \mathrm{eV}$ for $3 \mathrm{c}$. The low energy gaps suggest that that these compounds may be a promising new class of lead compounds for developing high performance semiconductor materials.

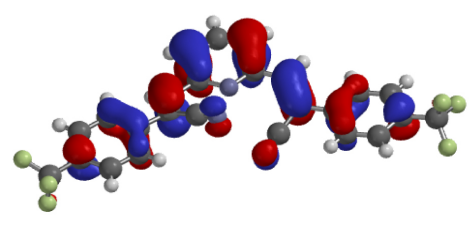

HOMO 3a $(-6.52 \mathrm{eV})$

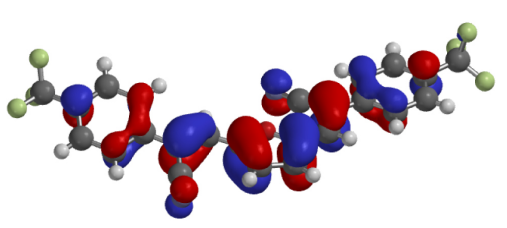

HOMO 3b $(-6.05 \mathrm{eV})$

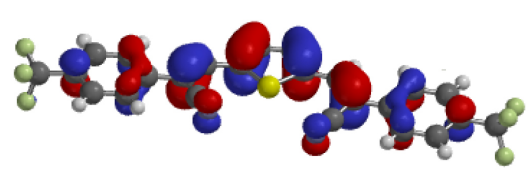

HOMO 3c (-5.93 eV)

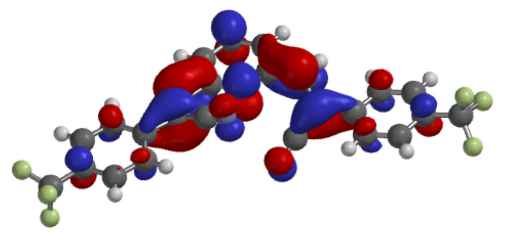

LUMO 3a $(-2.52 \mathrm{eV})$

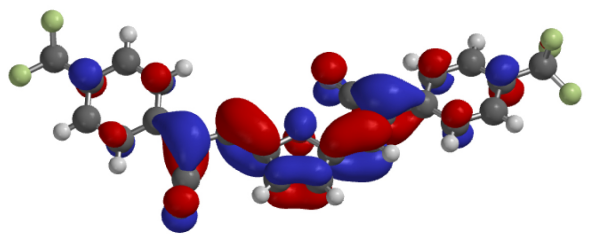

LUMO 3b (-3.07 eV)

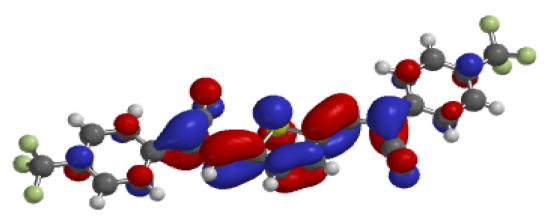

LUMO 3c (-3.93 eV)

Figure 9. HOMO and LUMO orbitals in the crystals of the compounds $3 a, 3 b$ and $3 c$. 


\section{Conclusion}

Three new -CF3, -CN containing $\pi$-conjugated heteroaromatic compounds consisting of pyridine $3 \mathrm{a}$, furan $3 \mathrm{~b}$, and thiophene $3 \mathrm{c}$ have been synthesized and these compounds have been characterized by ${ }^{1} \mathrm{H}$ NMR, EI-MS and X-ray diffraction analysis. Molecules $3 \mathrm{a}, \mathbf{3 b}$ and $3 \mathrm{c}$ showed strong absorption maxima wavelengths at 300, 419 and $418 \mathrm{~nm}$, respectively. The molar extinction coefficients $(\varepsilon)$ of the compounds $3 \mathrm{a}, 3 \mathrm{~b}$ and $3 \mathrm{c}$ indicated molecule $3 \mathrm{~b}$ has better ability to absorb UV light, molecule $\mathbf{3 a}$ has better fluorescence intensity than molecule $\mathbf{3 b}$ and 3c. Low energy gaps of HOMO and LUMO energy levels of these compounds suggest that these compounds may be a promising new class of lead compounds for developing high performance semiconductor materials. Compounds $3 \mathrm{a}, 3 \mathrm{~b}$ and $3 \mathrm{c}$ has emissions near to blue light, a slight modification of the structures by extending conjugation may find important applications in optoelectronic devices as blue light emitters in organic light-emitting devices.

\section{Acknowledgements}

We are grateful to the Center for Instrumental Analysis, Kyushu Institute of Technology (KITCIA) for the electron impact mass, ${ }^{1} \mathrm{HNMR}$ spectra and X-ray analysis. This research was financially supported by JSPS KAKENH Grant Number 15K05611.

\section{Conflicts of Interest}

The authors declare no conflicts of interest regarding the publication of this paper.

\section{References}

[1] Wang, C., Dong, H., Hu, W., Liu, Y. and Zhu, D. (2012) Semiconducting $\pi$-Conjugated Systems in Field-Effect Transistors: A Material Odyssey of Organic Electronics. Chemical Reviews, 112, 2208-2267. https://doi.org/10.1021/cr100380z

[2] Anthony, J.E. (2006) Functionalized Acenes and Heteroacenes for Organic Electronics. Chemical Reviews, 106, 5028-5048. https://doi.org/10.1021/cr050966z

[3] Blouin, N. and Leclerc, M. (2008) Poly(2,7-carbazole)s: Structure-Property Relationships. Accounts of Chemical Research, 41, 1110-1119. https://doi.org/10.1021/ar800057k

[4] Pron, A., Gawrys, P., Zagorska, M., Djurado, D. and Demadrille, R. (2010) Electroactive Materials for Organicelectronics: Preparation Strategies, Structural Aspects and Characterization Techniques. Chemical Society Reviews, 39, 577-2632. https://pubs.rsc.org/en/content/articlelanding/2010/cs/b907999h\#!divAbstract

[5] Wu, W., Liu, Y. and Zhu, D. (2010) $\pi$-Conjugated Molecules with Fused Rings for Organic Field-Effect Transistors: Design, Synthesis and Applications. Chemical Society Reviews, 39, 1489-1502.

https://pubs.rsc.org/en/content/articlelanding/2010/cs/b813123f/unauth\#!divAbstra ct

https://doi.org/10.1039/B813123F

[6] Yao, J., Yu, C., Liu, Z., Luo, H., Yang, Y., Zhang, G. and Zhang, D. (2016) Signifi- 
cant Improvement of Semiconducting Performance of the Diketopyrrolopyrrole-Quaterthio Phene Conjugated Polymer through Side-Chain Engineering via Hydrogen-Bonding. Journal of the American Chemical Society, 138, 173. https://doi.org/10.1021/jacs.5b09737

[7] Sutton, C., Risko, C. and Bredas, J.-L. (2016) Noncovalent Intermolecular Interactions in Organic Electronic Materials: Implications for the Molecular Packing vs Electronic Properties of Acenes. Chemistry of Materials, 28, 3-16. https://doi.org/10.1021/acs.chemmater.5b03266

[8] Aleshin, A.N., Lee, J.Y., Chu, S.W., Kim, J.S. and Park, Y.W. (2004) Mobility Studies of Field-Effect Transistor Structures Based on Anthracene Single Crystals. Applied Physics Letters, 84, 5383-5385. https://doi.org/10.1063/1.1767282

[9] Sokolov, A.N., Roberts, M.E. and Bao, Z. (2009) Fabrication of Low-Cost Electronic Biosensors. Materials Today, 12, 12-20.

https://www.sciencedirect.com/science/article/pii/S1369702109702470 https://doi.org/10.1016/S1369-7021(09)70247-0

[10] Kelley, T.W., Boardman, L.D., Dunbar, T.D., Muyres, D.V., Pellerite, M.J. and Smith, Y.P. (2003) High-Performance OTFTs Using Surface-Modified Alumina Dielectrics. The Journal of Physical Chemistry B, 107, 5877-5881. https://doi.org/10.1021/jp034352e

[11] Garnier, F., Yassar, A., Hajlaoui, R., Horowitz, G., Deloffre, F., Servet, B., Ries, S. and Alnot, P. (1993) Molecular Engineering of Organic Semiconductors: Design of Self-Assembly Properties in Conjugated Thiopheneoligomers. Journal of the American Chemical Society, 115, 8716-8721. https://doi.org/10.1021/ja00072a026

[12] Zaumseil, J. and Sirringhaus, H. (2007) Electron and Ambipolar Transport in Organic Field-Effect Transistors. Chemical Reviews, 107, 1296-1323. https://doi.org/10.1021/cr0501543

[13] Cornil, J., Bredas, J.L., Zaumseil, J. and Sirringhaus, H. (2007) Ambipolar Transport in Organic Conjugated Material. Advanced Materials, 19, 1791-1799. https://doi.org/10.1002/adma.200602922

[14] Newman, C.R., Frisbie, C.D., da Silva Filho, D.A., Bredas, J.-L., Ewbank, P.C. and Mann, K.R. (2004) Introduction to Organic Thin Film Transistors and Design of n-Channel Organic Semiconductors. Chemistry of Materials, 16, 4436-4451. https://doi.org/10.1021/cm049391x

[15] Swartz, C.R., Parkin, S.R., Bullock, J.E., Anthony, J.E., Mayer, A.C. and Malliaras, G.G. (2005) Synthesis and Characterization of Electron-Deficient Pentacenes. Organic Letters, 7, 3163-3166. https://doi.org/10.1021/ol050872b

[16] Kikuzawa, Y., Mori, T. and Takeuchi, H. (2007) Synthesis of 2,5,8,11,14,17Hexafluoro-hexa-peri-hexabenzocoronene for n-Type Organic Field-Effect Transistors. Organic Letters, 9, 4817-4820.

https://pubs.acs.org/doi/10.1021/ol702158a

https://doi.org/10.1021/ol702158a

[17] Song, D., Wang, H.B., Zhu, F., Yang, J.L., Tian, H.K., Geng, Y.H. and Yan, D.H. (2008) Phthalocyanato Tin(IV)Dichloride: An Air-Stable, High-Performance, n-Type Organic Semiconductor with a High Field-Effect Electron Mobility. Advanced Materials, 20, 2142-2144. https://doi.org/10.1002/adma.200702439 https://onlinelibrary.wiley.com/doi/abs/10.1002/adma.200702439

[18] Jones, B.A., Ahrens, M.J., Yoon, M.-H., Facchetti, A., Marks, T.J. and Wasielewski, M.R. (2004) High-Mobilityair-Stable n-Type Semiconductors with Processing Versatility: Dicyanoperylene-3,4,9,10-bis(dicarboximides). Angewandte Chemie Inter- 
national Edition, 43, 6363-6366. https://doi.org/10.1002/anie.200461324 https://onlinelibrary.wiley.com/doi/abs/10.1002/anie.200461324

[19] Jones, B.A., Facchetti, A., Wasielewski, M.R. and Marks, T.J. (2007) Tuning Orbital Energetics in Arylene Diimide Semiconductors. Materials Design for Ambient Stability of n-Type Charge Transport. Journal of the American Chemical Society, 129, 15259-15278. https://pubs.acs.org/doi/10.1021/ja075242e

[20] Nagamatsu, S., Moriguchi, T., Nagase, T., Oku, S., Kuramoto, K., Takashima, W., Okauchi, T., Mizoguchi, K., Hayase, S. and Kaneto, K. (2009) A Steady Operation of n-Type Organic Thin-Film Transistors with Cyano-Substituted Distyrylbenzene Derivative. Applied Physics Express, 2, Article ID: 101502.

http://iopscience.iop.org/article/10.1143/APEX.2.101502 https://doi.org/10.1143/APEX.2.101502

[21] Nagamatsu, S., Oku, S., Kuramoto, K., Moriguchi, T., Takashima, W., Okauchi, T. and Hayase, S. (2014) Long-Term Air-Stable $n$-Channel Organic Thin-Film Transistors Using 2,5-Difluoro-1,4-phenylene-bis\{2-[4-(trifluoromethyl)phenyl] acrylonitrile\}. Applied Materials \& Interfaces, 6, 3847-3852.

https://pubs.acs.org/doi/abs/10.1021/am404549e https://doi.org/10.1021/am404549e

[22] (2009) APEX2 Version 2009.9. Bruker AXS Inc., Tokyo.

[23] (2009) SAINT Version 7.68A. Bruker AXS Inc., Tokyo.

[24] Sheldrick, G.M.A. (2008) Short History of SHELX. Acta Crystallographica A, 64, 112-122. https://doi.org/10.1107/S0108767307043930

[25] Halgren, T.A. (1996) Merck Molecular Force Field. I. Basis, Form, Scope, Parameterization, and Performance of MMFF94. Journal of Computational Chemistry, 17, 490-519.

https://doi.org/10.1002/(SICI)1096-987X(199604)17:5/6<490::AID-JCC1>3.0.CO;2$\underline{\mathrm{P}}$ 